\title{
From the Editor
}

Volume 2, Issue 3 of Integritas addresses the question of how core curricula at Catholic colleges and universities reflect a commitment to the liberal arts. The historian David Quigley, Dean of Arts and Sciences at Boston College, first looks at the history of the modern core in Catholic institutions in the United States, pointing out the variety of approaches that have emerged over generations. He goes on to reflect upon the process of core curriculum renewal at Boston College, a process yet unfinished at the time of this publication.

The physicist John Cunningham of Loyola University responds to Quigley's essay, raising questions about the different ways that students and faculty view the core. As a scientist, he is aware of the explosion of knowledge in the twentieth century, and yet he observes that some of the more fundamental questions facing human beings today are not all that different from a century and a half ago. Even as his own students raise questions about advanced scientific research, he shows an appreciation for the importance of thinking critically about the liberal arts.

The lively discussion that followed this paper and response is captured in the last segment of this issue. Many participants in the Roundtable have been part of core renewal discussions and shared some of their reflections on the neuralgic questions underneath these discussions. What is evident is that any discussion of the liberal arts in the context of the core curriculum raises fundamental questions about the nature and purposes of university education as a whole. Catholic colleges and universities are in a unique position in the landscape of contemporary higher education, able to draw from the strength of their historic commitment to the liberal arts as a preparation for life in a complex globalized world.

Tim Muldoon

muldoont@bc.edu 